\title{
Ectopia cordis: Un extraño caso de anomalía cardíaca congénita
}

\section{Ectopia Cordis: A Rare Case of Congenital Cardiac Anomaly}

\author{
Brian Daniel Noreña Rengifo ${ }^{10}$ \\ José Fernando Vallejo Díaz ${ }^{3}$ \\ ${ }^{1}$ Universidad de Antioquia Facultad de Medicina, Medellín, Antioquia, \\ Colombia \\ 2 Universidad CES, Medellín, Colombia \\ ${ }^{3}$ Centro Médico Imbanaco, Cali, Colombia
} Address for correspondence Brian Daniel Noreña Rengifo, MD,
Universidad de Antioquia Facultad de Medicina, Calle 70 No. 52-21,
Medellín, Antioquia, Colombia (e-mail: brian.norena@udea.edu.co).

Rev Argent Radiol 2020;84:130-132.

Estimados editores,

La ectopia cordis (EC) es una anomalía congénita poco frecuente que consiste en la mala posición del corazón por fuera de la cavidad torácica, secundaria a un defecto en la fusión de las paredes torácica y abdominal, como resultado de una mala fusión ventromedial de los pliegues corporales. ${ }^{1}$ Hasta el año 2014 se habían reportado menos de 100 casos de esa patología. ${ }^{2}$ Su diagnóstico se basa en la detección por imágenes de la posición inadecuada del corazón y, por ende, la evidencia de latido cardíaco por fuera de la cavidad torácica, siendo ese diagnóstico generalmente prenatal por medio de ultrasonido. ${ }^{3}$ El pronóstico es pobre, debido a que la mayoría de los pacientes tienen otras anomalías cardíacas asociadas. ${ }^{1,4}$

Comunicamos el caso de una recién nacida pre-término de 33 semanas, sexo femenino, hija de primigestante con embarazo gemelar, con diagnóstico de EC in útero por ecografías prenatales. Nacimiento por cesárea por pérdida de bienestar fetal, con peso de $1,282 \mathrm{gr}$ y talla de $38 \mathrm{~cm}$. Al examen físico con hipotensión y taquipnea. En la línea media del tórax con defecto asociado a EC. Inicialmente se realizó radiografía de tórax ( $\mathbf{- F i g . 1}$ ).

Debido a dificultades técnicas para realizar el ecocardiograma, se solicitó angiotomografía (angioTC) de corazón y grandes vasos (-Figs. 2 y 3 ) que confirma la EC adyacente al tórax, ausencia de esternón, conducto arterioso permeable, comunicación interauricular (CIA), comunicación interventricular (CIV) muscular a nivel del ápex, aorta con acabalgamiento sobre el septum interventricular y arteria subclavia derecha de origen aberrante. La paciente fue llevada a corrección quirúrgica, pero falleció en el postquirúrgico inmediato.
La EC, también llamada ectocardia o exocardia, fue reportada por primera vez por Stenonis en 1671 y el término fue creado por Haller en $1706 .^{1,2,5-7}$ La prevalencia es de 5 a 8 por cada millón de nacidos vivos. ${ }^{8}$ La mayoría de los pacientes (95\%) presentan otras anomalías cardíacas asociadas y eso empeora el pronóstico. ${ }^{1,9}$ Las alteraciones intracardíacas más comunes son los defectos del septo interventricular y en el septo interatrial; menos frecuentemente se presentan la tetralogía de Fallot (20\%), el divertículo ventricular izquierdo (20\%), la vena cava superior izquierda (12\%) y doble salida del ventrículo derecho $(13 \%)^{2,9}$ Nuestra paciente se presentó con los dos defectos intracardíacos más comunes, la CIV y la CIA, lo que apoya reportes previos de pacientes con EC.

Dependiendo de la localización del corazón, la EC se clasifica en 5 tipos: : $^{1,9,9,10}$

- Cervical (5\%): El corazón en el cuello sin defectos esternales asociados. Puede haber fusión entre el ápex del corazón y la boca. ${ }^{1,6,9}$

- Cervicotorácico y torácico (65\%): Defecto en la región superior del esternón en la cervicotorácica y una protrusión del corazón por la pared anterior del tórax, también por un defecto esternal en la variedad torácica. En esa última variedad, se encuentra la disminución del volumen intratorácico que se puede determinar por medio de la tomografía computarizada (TC). ${ }^{1,2,6,9}$ Se ha reportado sobrevida de $<5 \%$ después del primer mes de vida. ${ }^{1,6}$

- Toracoabdominal (20\%): Defecto en el septum transverso en la porción inferior del esternón y el epigastrio. ${ }^{1,4,9} \mathrm{La}$ received

October 31, 2019

accepted

April 14, 2020
DOI https://doi.org/

10.1055/s-0040-1713090.

ISSN 1852-9992.
Copyright ( $)$ 2020, Sociedad Argentina de Radiología. Publicado por Thieme Revinter Publicações Ltda., Rio de Janeiro, Brazil. Todos los derechos reservados.

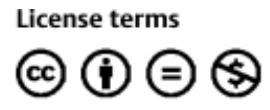




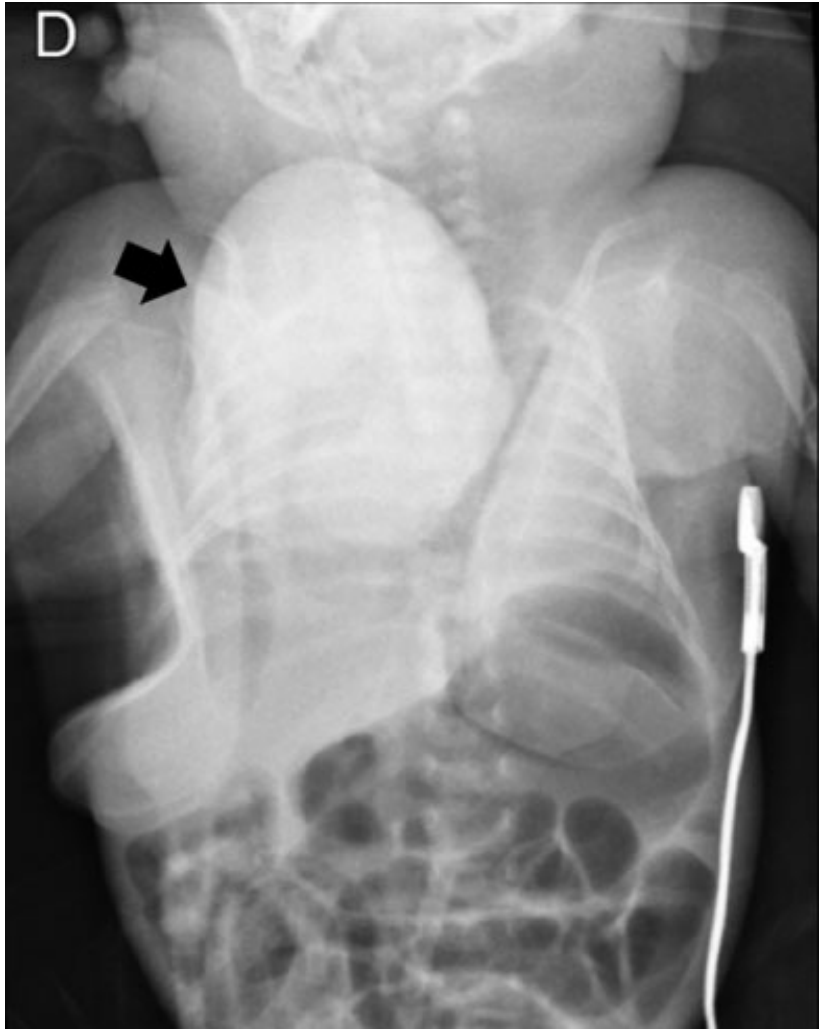

Fig. 1 Radiografía de tórax. Silueta cardiaca extra torácica (flecha negra) y aumento en la opacidad pulmonar bilateral.

posición del corazón es variable, pudiendo estar parcialmente en la cavidad torácica o completamente en el abdomen. También se encuentran lesiones cardiacas intrínsecas asociadas.

- Abdominal (10\%): Defecto en el diafragma y el corazón se ubica en el abdomen superior. ${ }^{1,9}$ Esos pacientes, al igual que los pacientes con variedad toracoabdominal, se pueden asociar a defectos de la pared abdominal como onfalocele, diastisis de los rectos o hernia ventral. ${ }^{6}$

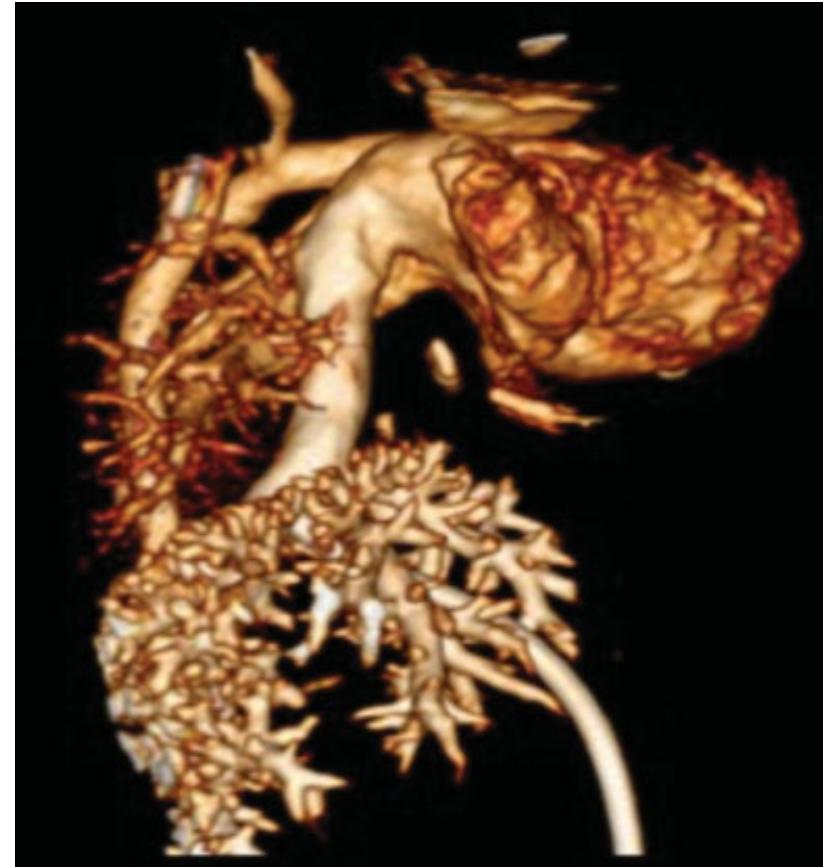

Fig. 3 Reconstrucción tridimensional. Corazón extra torácico y dilatación de la vena cava inferior, con persistencia de los grandes vasos intra torácicos.

Las causas de esa malformación son desconocidas y generalmente es una malformación esporádica. ${ }^{1,9}$ Existen reportes de casos que asocian la EC con anormalidades cromosómicas como trisomía 18 , síndrome de Turner y 46, $\mathrm{XX}, 17 \mathrm{q}+.{ }^{4,10}$

El complejo de pared abdominal-miembros consiste en EC, toracoabdominoquisis o abdominoquisis, defectos en las extremidades y craneofaciales (labio y paladar hendido, encefalocele, exencefalia, entre otros). ${ }^{4,8-10}$ La pentalogía de Cantrell incluye la EC toracoabdominal, defecto del pericardio anterior, solución de continuidad en el esternón y en la porción anterior del diafragma y malformaciones intracardíacas., ${ }^{4,9,10}$
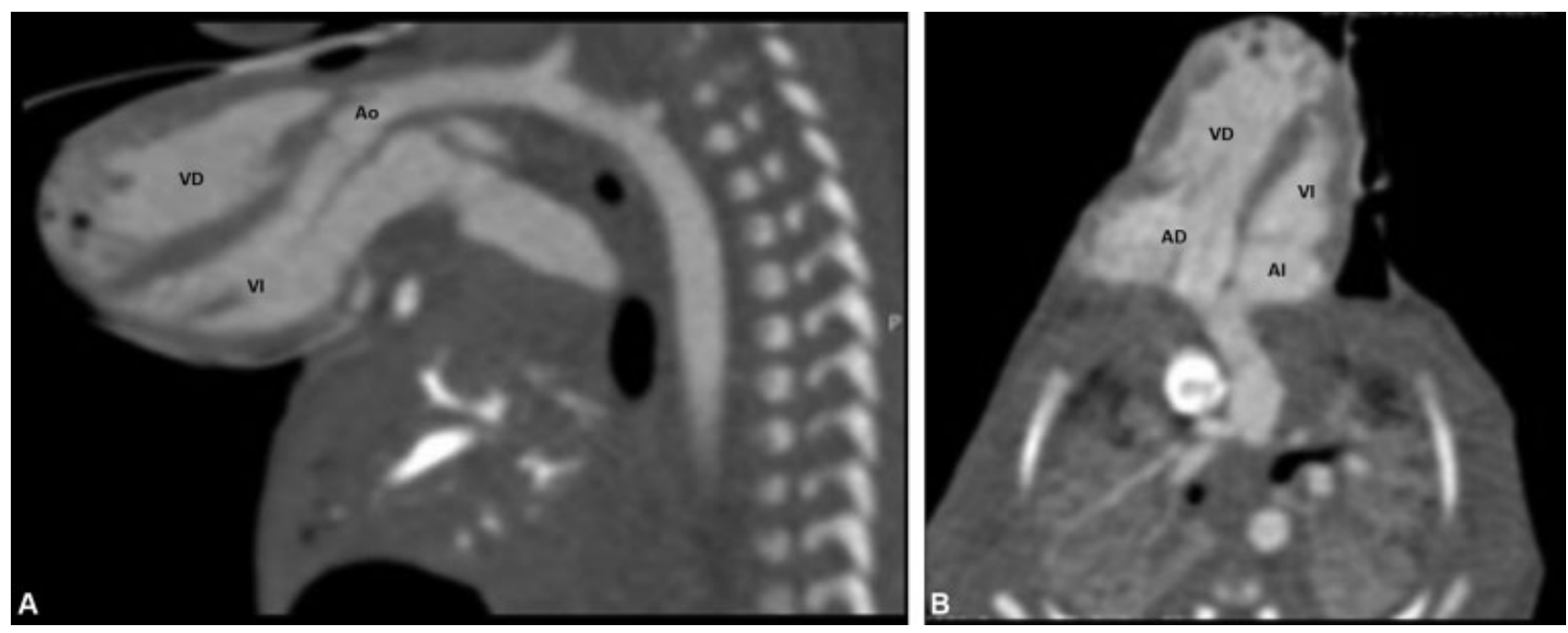

Fig. 2 AngioTC de tórax. Corazón extra torácico evidenciado en reconstrucciones en los planos sagital (A) y axial (B), sin recubrimiento de piel, sincrónico y concordante, demostrando adecuada relación entre la aurícula derecha (AD) y el ventrículo derecho (VD) y entre la aurícula izquierda (AI) y el ventrículo izquierdo (VI), al igual que con la aorta (Ao). 
La ultrasonografía prenatal permite el diagnóstico de la EC tan temprano, como a las semanas 7-8 de gestación, con mayor probabilidad de diagnóstico al evaluar en modo Doppler y 3D. Sin embargo, muchos autores mencionan que el diagnóstico suele ser entre la semana 10 y 13 , con mejor caracterización de los hallazgos después de la semana 15 . $^{1,4,8,10}$

La ecocardiografía es el método más importante en el diagnóstico postnatal, pero tiene la posibilidad de lesiones o infecciones. La TC permite evaluar de forma fácil el volumen torácico y puede ser útil en la planeación quirúrgica, con la ventaja de su rápida adquisición, las imágenes multiplanares y 3D de alta resolución. Cabe mencionar como limitante el uso de medios de contraste yodado y la radiación ionizante.

En casos de obesidad materna, oligohidramnios, gestación múltiple y embarazo avanzado, se puede requerir de resonancia magnética $(\mathrm{RM}) .^{8}$ A pesar de su largo tiempo de adquisición, es útil en casos de anomalías complejas, para planear vía del parto y definir intervenciones pre y postnatales. ${ }^{4,8}$ El protocolo de RM incluye secuencias como turbo espín eco (TSE) potenciadas en T2 en 3 planos ortogonales del cuerpo fetal y eco gradiente potenciada en T1. ${ }^{8}$

Confidencialidad de los Datos

Los autores declaran que han seguido los protocolos de su centro de trabajo sobre la publicación de datos de pacientes y que todos los pacientes incluidos en el estudio han recibido información suficiente y han dado su consentimiento informado por escrito.
Conflicto de Intereses

Los autores del trabajo declaran no tener ningún conflicto de intereses.

\section{Bibliografía}

1 Shad J, Budhwani K, Biswas R. Thoracic ectopia cordis. BMJ Case Rep. 2012;2012:2012

2 Abigail G, Donnelly J, Kuc A, Good D, Doros G, Matusz P, et al. Ectopia cordis: a rare congenital anomaly. Clin Anat. 2014;27(08): 1193-1199

3 Tongsong T, Wanapirak C, Sirivatanapa P, Wongtrangan S. Prenatal sonographic diagnosis of ectopia cordis. J Clin Ultrasound. 1999; 27(08):440-445

4 Pius S, Abubakar Ibrahim H, Bello M, Bashir Tahir M. Complete Ectopia Cordis: A Case Report and Literature Review. Case Rep Pediatr. 2017;2017:1858621

5 Taussig HB. World survey of the common cardiac malformations: developmental error or genetic variant? Am J Cardiol. 1982;50 (03):544-559

6 Shamberger RC, Welch KJ. Sternal defects. Pediatr Surg Int. 1990; 5:156-164

7 Millhouse RF, Joos HA. Extrathoracic ectopia cordis: report of cases and review of literature. Am Heart J. 1959;57(03):470-476

8 Torres US, Portela-Oliveira E, Braga FdelC, Werner H Jr, Daltro PA, Souza AS. When Closure Fails: What the Radiologist Needs to Know About the Embryology, Anatomy, and Prenatal Imaging of Ventral Body Wall Defects. Semin Ultrasound CT MR. 2015;36 (06):522-536

9 Cabrera A, Rodrigo D, Luis MT, Pastor E, Galdeano JM, Esteban S. [Ectopia cordis and cardiac anomalies]. Rev Esp Cardiol. 2002;55 (11):1209-1212

10 Quiroga HG. Ectopia Cordis: Diagnóstico ecográfico en el segundo trimestre de la gestación. Rev Chil Obstet Ginecol. 2004;69(05): 372-375 